
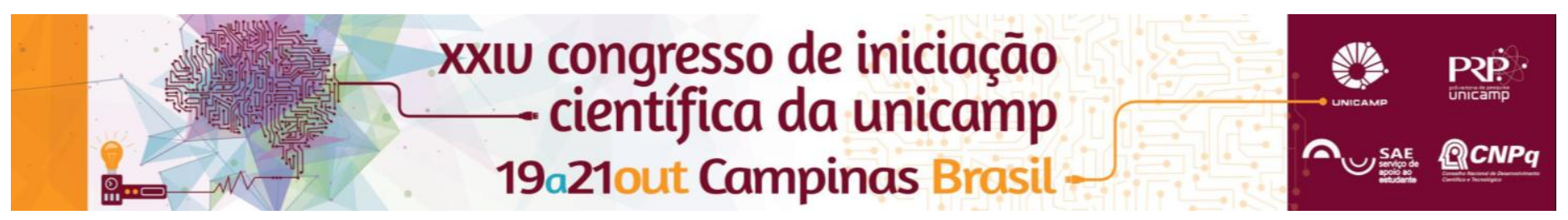

\title{
ESTRUTURAS AERONÁUTICAS DE MATERIAIS COMPÓSITOS
}

\section{Renan H. M. Callegari *, José Pissolato Filho.}

\section{Resumo}

Visando inovações tecnológicas na indústria aeronáutica o projeto busca a validação para uso aeronáutico de novas tecnologias, processos, métodos e critérios, de modo a efetivar o ciclo de desenvolvimento de novas soluções estruturais em compósitos. A parte do projeto pela qual a iniciação cientifica está responsável é o estudo sobre efeitos diretos de descargas atmosféricas em aeronaves, a qual envolve testes com descargas elétricas similares a um raio nos compósitos que representam a fuselagem da aeronave, afim de obter dados e estudos das características físicas dos materiais após a descarga.

\section{Palavras-chave:}

Estruturas, Aeronaves, Compósitos

\section{Introdução}

Em geral, após um período de estiagem prolongada as chuvas são caracterizadas por apresentarem-se sob o aspecto de fortes tempestades. Estas são sempre acompanhadas por descargas elétricas que, em geral, afetam as aeronaves. Com a evolução tecnológica estendendo-se cada vez mais às aeronaves, estudos devem ser realizados para investigar o comportamento dessas estruturas quando as mesmas são atingidas por uma corrente elétrica de alta intensidade, proveniente de descarga atmosférica. $O$ projeto tem como objetivo o desenvolvimento e validação de uma metodologia para ensaios de efeitos diretos de descargas atmosféricas em aeronaves, incluindo a realização de impactos diretos de correntes. Visando também a equipagem da Unicamp para realização desse tipo de ensaios e a independência de empresas internacionais para a execução desse tipo de ensaio.

\section{Resultados e Discussão}

Antes de realizar os testes de descargas de corrente nos materiais que compõe a fuselagem da aeronave, apresentado na Figura 1, foram feitas algumas simulações através do software CST [1].

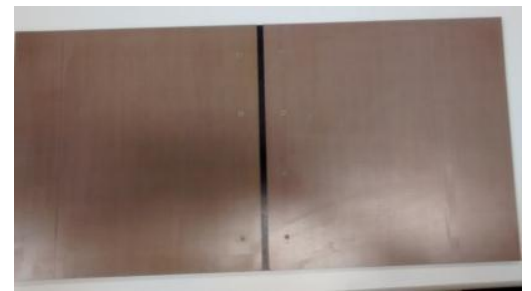

Figura 1. Compósito de carbono utilizado nos testes.

A metodologia adotada nas simulações foi a mesma utilizada nos testes em laboratório. Estas simulações foram realizadas com o intuito de obter-se um resultado prévio para uma futura comparação e validação com os testes. Com base nas simulações observamos uma maior concentração da corrente nas bordas do material, assim o próximo passo foi realizar os testes em laboratório e compararmos os resultados obtidos.
Para os testes em laboratório foram utilizados vários materiais iguais ao apresentado na Figura 1. Os testes consistem na aplicação de uma corrente de $200 \mathrm{kA}$ (mil ampères) no material, de modo a simular uma descarga atmosférica. Após as aplicações os materiais apresentaram as seguintes características, como representadas na Figura 2.

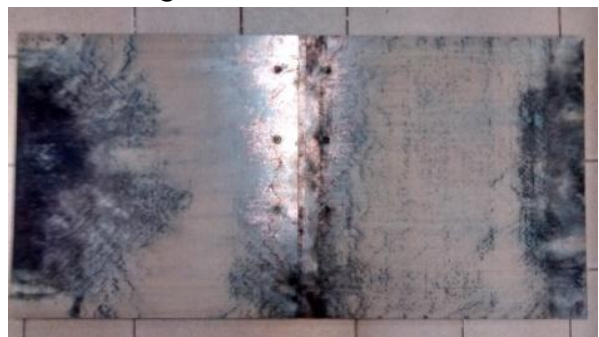

Figura 2. Material após a descarga de corrente.

Com isso, podemos dizer que os testes contemplam as simulações pois, é evidente que o dano causado pelo fluxo da corrente é mais acentuado nas bordas do material.

\section{Conclusões}

Finalizado os testes concluímos que o material sofre maior dano em suas extremidades e junções, com isso surgem alguns pontos a serem melhor explorados em relação ao comportamento da corrente no material. Futuramente 0 projeto visa através de simulações estudar melhor o comportamento da corrente quando esta flui através do material, assim será possível obter respostas mais concretas e buscar soluções que minimizem o dano causado no material, o qual é o mesmo utilizados em aeronaves.

\section{Agradecimentos}

Deixo aqui meus agradecimentos a toda equipe do Laboratório de Alta Tensão (LAT) da Unicamp que colaborou com todo o desenvolvimento deste projeto.

[1] https://www.cst.com/products/CSTMWS. 